\title{
Butyrylcholinesterase as a marker of inflammation and liver injury in the acute and subclinical phases of canine ehrlichiosis
}

\author{
Guilherme M. do Carmo ${ }^{\mathrm{a}}$, Leandro Z. Crivellenti ${ }^{\mathrm{b}, \mathrm{c}, *}$, Nathieli B. Bottari ${ }^{\mathrm{a}}$, \\ Gustavo Machado $^{\mathrm{d}}$, Sofia Borin-Crivellenti ${ }^{\mathrm{b}}$, Rafael N. Moresco ${ }^{\mathrm{e}}$, Thiago Duarte ${ }^{\mathrm{f}}$, \\ Marta Duarte $^{g}$, Mirela Tinucci-Costa ${ }^{\mathrm{b}}$, Vera M. Morsch ${ }^{\mathrm{a}}$, Maria Rosa C. Schetinger ${ }^{\mathrm{a}}$, \\ Lenita M. Stefani ${ }^{\mathrm{h}}$, Aleksandro S. Da Silva ${ }^{\mathrm{h}, *}$ \\ a Programa de Pós-Graduação em Bioquímica Toxicológica, Universidade Federal de Santa Maria, Santa Maria, RS, Brazil \\ ${ }^{\mathrm{b}}$ Department of Veterinary Clinic and Surgery, Universidade Estadual Paulista "Júlio de Mesquita Filho“, Jaboticabal, SP, Brazil \\ ${ }^{\mathrm{c}}$ Department of Veterinary Clinic and Surgery, Universidade de Franca, Franca, SP, Brazil \\ ${ }^{\mathrm{d}}$ Laboratory of Veterinary Epidemiology, Faculty of Veterinary, Universidade Federal do Rio Grande do Sul, Porto Alegre, RS, Brazil \\ e Department of Clinical and Toxicological Analysis, Universidade Federal de Santa Maria, Santa Maria, RS, Brazil \\ f Programa de Pós-Graduação em Farmacologia, Universidade Federal de Santa Maria, Santa Maria, RS, Brazil \\ g Universidade Luteranda do Brasil-ULBRA, Santa Maria, RS, Brazil \\ ${ }^{\mathrm{h}}$ Department of Animal Science, Universidade do Estado de Santa Catarina (UDESC), Chapecó, SC, Brazil
}

\section{A R T I C L E I N F O}

\section{Article history:}

Received 21 May 2015

Received in revised form 2 September 2015

Accepted 25 September 2015

\section{Keywords:}

BChE

Ehrlichia canis

Inflammation marker

\begin{abstract}
A B S T R A C T
The aim of this study was to evaluate the role of butyrylcholinesterase (BChE) as a marker of inflammation and liver injury in the acute and subclinical phases of canine ehrlichiosis. Forty-two serum samples of dogs naturally infected with Ehrlichia canis were used, of which 24 were from animals with the acute phase of the disease and 18 with subclinical disease. In addition, sera from 17 healthy dogs were used as negative controls. The hematocrit, BChE activity, hepatic injury (alanine aminotransferase (ALT) and aspartate aminotransferase (AST)), nitric oxide, and cytokines levels were evaluated. The BChE activity was significantly elevated $(P<0.05)$ in dogs with the acute phase of the disease when compared to healthy animals. However, there was a reduction on $\mathrm{BChE}$ activity on dogs with subclinical disease compared to the other two groups. AST and ALT levels were significantly higher $(P<0.05)$ in the acute phase, as well as the inflammatory mediators $\left(\mathrm{NO}_{x}\right.$, TNF- $\alpha$, INF- $\gamma$, IL-4, IL-6) when compared to the control group. On the other hand, IL-10 levels were lower in the acute phase. Based on these results, we are able to conclude that the acute infection caused by $E$. canis in dogs leads to an increase on seric BChE activity and some inflammatory mediators. Therefore, this enzyme might be used as a marker of acute inflammatory response in dogs naturally infected by this bacterium.
\end{abstract}

ㄷ 2015 Elsevier Ltd. All rights reserved.

\section{Introduction}

Canine ehrlichiosis is a disease caused by a gram-negative obligate intracellular bacterium known as Ehrlichia canis [1-3], mainly transmitted by Rhicephalus sanguineus ticks [4,5]. E. canis is a widely distributed pathogen, more prevalent in tropical regions of the world [6], responsible for serious life-threatening

\footnotetext{
* Corresponding authors at: Universidade do Estado de Santa Catarina (UDESC), Animal Science, Prédio Zootecnia, 97105-900 Chapecó, SC, Brazil. Tel.: +55 49 33309432; fax: +55 4933224202.

E-mail addresses: crivellenti_lz@yahoo.com.br (L.Z. Crivellenti), dasilva.aleksandro@gmail.com (A.S. Da Silva).
}

illness in dogs [7]. The disease course has three forms: acute, subclinical, and chronic. In the acute form, infected animals may show fever, lethargy, bruising, petechial hemorrhage, weight loss, hepatomegaly, splenomegaly, cardiorespiratory disorders, thrombopenia, and leukopenia followed by leukocytosis. On the other hand, dogs with the subclinical form of the disease are asymptomatic $[2,8,9]$. It is possible that these differences on disease pathogenesis caused by $E$. canis might be related to other factors to host's immune responses, which are not fully understood.

The cytokine profile found in rickettsial diseases has been suggested to be composed of pro-inflammatory cytokines (IL1 $\beta$, IL-6, IL-12, and TNF- $\alpha$ ) associated to clinical aggravation of disease with activation of inflammatory cells and nitric oxide production by macrophages [10]. However, cytokines such as IL-10 and 
TGF- $\beta$ may be involved in immune response modulation and disease remission [11]. According to the literature, canine acute ehrlichiosis is a febrile disease with severe hematological disorders; from the moment these pathogens penetrate the animal's body, there is a quick dissemination of them through not well-known mechanisms, in addition to an ineffective host immune response [10]. Therefore, it is pertinent to investigate other mechanisms or systems involved in the host's immune response against $E$. canis by accessing the role of cholinesterases, a well-known marker of the inflammation process [12].

Cholinesterase represents a group of enzymes that hydrolyzes acetylcholine and other choline esters [13] known as acetylcholinesterase (AChE) and butyrylcholinesterase (BChE) [14], and they are involved in neurotransmission, motor coordination, memory, hematopoiese [15], and anti-inflammatory responses [12]. The BChE is produced by the liver [16], but can be also found in the serum, pancreas, kidney, and central nervous system [17], and its activity is related to the inflammatory process [12]. According to the literature, $\mathrm{BChE}$ can be a prognostic marker of disease, since low enzymatic levels have been correlated to higher risk of mortality [16]. Therefore, the aim of this study was to evaluate the participation of $\mathrm{BChE}$ in the inflammatory response of dogs naturally infected by $E$. canis in the acute and subclinical phases of the disease.

\section{Materials and methods}

\subsection{Animals}

In this study, 42 serum samples were collected from dogs naturally infected by $E$. canis, of which 24 were from animals showing clinical signs with the acute phase of the disease, and 18 were from animals with subclinical disease (asymptomatic), but PCR positives to E. canis. As a negative control group, serum samples from 17 healthy dogs were also used. The group with acute disease was composed of 15 females and 9 males with an average age of $3.18 \pm 2.95$, ranging from 4 months to 10 years. On the other hand, the group with subclinical disease had 11 females and 6 males with an age average of $4.1 \pm 3.3$, ranging from 6 months to 9 years. In addition, the control group had 8 females and 11 males, with age average of $3.1 \pm 3.0$ (range of 3 months to 8 years).

Animal history, clinical signs, complete blood work, biochemical profile, molecular testing's were performed on each dog in order to confirm the diagnosis of $E$. canis and rule out some other diseases. Blood samples were tested for the presence of $E$. canis, Babesia sp., Anaplasma platys using a previously described nested PCR technique [18-20], and we have found that these animals were positives only for E. canis. For PCR analyses, genomic DNA was extracted from whole blood following the procedures used routinely by the Laboratório de Diagnóstico Molecular Veterinário do Instituto de Biociências of UNESP Campus in Botucatu, São Paulo, Brazil.

\subsection{Hematocrit}

Blood was collected by jugular puncture, stored on appropriate tubes containing EDTA, and hematocrit examination was performed using the Standard Microhematocrit method (Centimicro mod. 1-15-Sigma, Germany).

\subsection{BChE activity}

The BChE enzymatic assay for sera was performed as described by Ellman [21] using butyrylthiocholine as a substrate. Sample analyses were carried out in duplicate, and the enzyme activity was expressed in $\mu$ moles $\mathrm{BcSCh} / \mathrm{h} / \mathrm{mg}$ of protein.

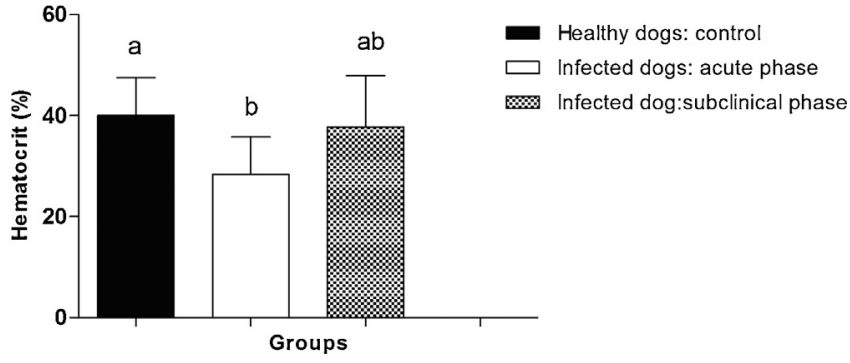

Fig. 1. Hematocrit of healthy (control group), and Ehrlichia canis naturally infected dogs showing acute and subclinical phases of the disease. Different letters in the graph demonstrate statistical difference between groups $(P<0.05)$.

\subsection{Hepatic evaluation}

Hepatic function was evaluated in this study since BChE is produced in the liver. Thus, seric activities of alanine aminotransferase (ALT), aspartate aminotransferase (AST), gammaglutamyltransferase (GGT), alkaline phosphatases (PAL), and triglycerides and cholesterol were evaluated using Cobas Mira ${ }^{\circledR}$ analyzer (Roche Diagnostics, Basel, Switzerland) with commercial kits $\left(\right.$ Bioclin $\left.^{\circledR}\right)$. Tests were carried out in duplicate.

\subsection{Nitric oxide and cytokines levels}

Nitric oxide levels in sera of dogs were evaluated indirectly by nitrite/nitrate $\left(\mathrm{NO}_{x}\right)$ quantification according to the technique described by Tatsch et al. [22], using modified Griess method and Cobas Mira automated analyzer. $\mathrm{NO}_{x}$ results were expressed as $\mu \mathrm{mol} \mathrm{L}^{-1}$.

Tumor necrosis factor alpha (TNF- $\alpha$ ), interferon gamma (INF- $\gamma$ ), and interleukins (IL-4, IL-6, and IL-10) levels were assessed through Enzyme Linked Immuno Sorbent Assay (ELISA) using commercial kits specific for dogs (Milliplex ${ }^{\circledR}$ MAP) and according to the manufacturer's instructions. The concentration of the cytokines was determined by the intensity of the color measured spectrophotometrically using a microplate reader. All tests were performed in duplicate.

\subsection{Statistical analysis}

The data from infected dogs were first analyzed descriptively, where measures of central tendency (median) and data dispersion (range that stands for the interval between the minimum and maximum values in the data) were computed. Further, all variables were submitted to Shapiro Wilk's $W$-test for normally distribution verification, and since most of the variables did not met the assumption of parametric testing, a nonparametric test was used for three independent groups Kruskal-Wallis test. Correlation among BChE and AST, ALT, GGT, PAL, TNF- $\alpha$, and IFN- $\gamma$ was also tested by Sperman Rank correlation test. It was considered statistically different when $P$ value was $<0.05$.

\section{Results}

\subsection{Clinical evaluation and hematocrit}

Dogs from the control group and those with subclinical disease caused by E. canis showed no apparent clinical signs, unlike those dogs with the acute infection that showed various clinical signs such as apathy, appetite loss, and fever. In addition, the hematocrit of dogs with acute infection was lower compared to healthy dogs (Fig. 1). It is important to point out that more than $40 \%$ of the dogs with acute infections had ticks. 
Table 1

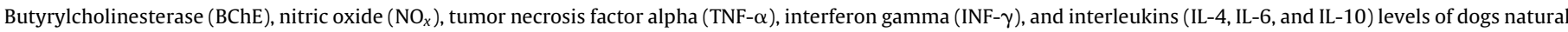
infected by Ehrlichia canis (acute and subclinical phases) compared to healthy dogs (control).

\begin{tabular}{|c|c|c|c|}
\hline Variables & Healthy dogs (control) & Infected dogs (acute phase) & Infected dogs (subclinical) \\
\hline BChE & $11.48(7.6-12.74)^{b}$ & $14.88(11.51-24.2)^{\mathrm{a}}$ & $8.30(5.14-12.69)^{c}$ \\
\hline $\mathrm{NO}_{x}\left(\mu \mathrm{mol} \mathrm{L}^{-1}\right)$ & $446.8(76.40-1218.80)^{c}$ & $822(648.80-2109.9)^{a}$ & $568(53.80-1735.80)^{b}$ \\
\hline TNF- $\alpha\left(p g \mathrm{~mL}^{-1}\right)$ & $75(65.0-90.0)^{c}$ & $177(138.00-194.0)^{\mathrm{a}}$ & $150.5(121.0-160.0)^{\mathrm{b}}$ \\
\hline $\mathrm{IFN}-\gamma\left(\mathrm{pg} \mathrm{mL}^{-1}\right)$ & $61.5(57.0-80.0)^{c}$ & $164(129.0-187.0)^{\mathrm{a}}$ & $138.5(117.0-155.0)^{b}$ \\
\hline $\mathrm{IL}-4\left(\mathrm{pg} \mathrm{mL} \mathrm{L}^{-1}\right)$ & $43.5(37.0-57.0)^{c}$ & $161.5(144.0-190.0)^{a}$ & $129.5(119.0-141.0)^{\mathrm{b}}$ \\
\hline IL-6 $\left(\mathrm{pg} \mathrm{mL}^{-1}\right)$ & $51.5(44.0-63.0)^{c}$ & $144(118.0-167.0)^{\mathrm{a}}$ & $105.5(85.0-140.0)^{\mathrm{b}}$ \\
\hline IL-10 $\left(\mathrm{pg} \mathrm{mL}^{-1}\right)$ & $70.5(54.0-94.0)^{\mathrm{a}}$ & $30(17.0-54.0)^{c}$ & $55.5(39.0-70.0)^{\mathrm{b}}$ \\
\hline
\end{tabular}

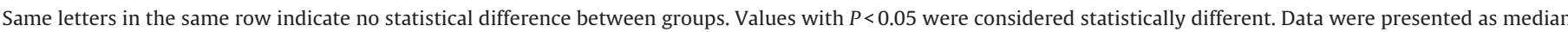
and range values (minimum-maximum).

\subsection{Seric BChE activity}

$\mathrm{BChE}$ results were shown in Table 1. Animals with acute infection by $E$. canis had a significant increase $(P<0.05)$ in seric $B C h E$ activity compared to healthy animals. On the other hand, seric BChE activity was reduced on dogs with subclinical infection compared to the other two groups.

\subsection{Inflammatory mediators and BChE activity}

$\mathrm{NO}_{x}$, TNF- $\alpha$, INF- $\gamma$, IL-4, IL-6 and IL-10 data are shown in Table 1. A significant difference $(P<0.05)$ among the three groups was observed for all studied variables, and an obvious increase was noticed for $\mathrm{NO}_{x}$, TNF- $\alpha$, INF- $\gamma$, IL-4, and IL- 6 levels on dogs with the acute phase of the disease in comparison to the control and subclinical groups. On the contrary, IL-10 levels were lower on the acute phase of the disease. Fig. 2 shows significant correlations among dogs with ehrlichiiosis on different phases of the disease: $\mathrm{BChE}$ and TNF- $\alpha$ on the subclinical phase $(r=-0.28, P=0.001)$; BChE and TNF- $\alpha$ on the acute phase $(r=0.04, P=0.02)$; BChE and INF- $\gamma$ on the subclinical phase $(r=-0.28, P=0.001)$, and BChE and INF- $\gamma$ on the acute phase $(r=0.03, P=0.04)$.

\subsection{Hepatic function and BChE activity}

ALT, AST, GGT and PAL results are shown in Table 2. Significant differences $(P<0.05)$ were observed among the three studied groups for all variables. On the acute phase, AST and ALT activities were increased compared to control and subclinical groups. On the other hand, GGT and PAL levels were higher on the subclinical phase of the disease. Fig. 3 shows significant correlation between $\mathrm{BChE}$ and AST on the subclinical phase $(r=-0.32, P=0.001)$; between $\mathrm{BChE}$ and AST on the acute phase $(r=0.27, P=0.02)$; between $\mathrm{BChE}$ and ALT on the subclinical phase $(r=-0.13, P=0.001)$; and between $\mathrm{BChE}$ and ALT on the acute phase $(r=0.10, P=0.03)$. No correlation was observed between BChE, GGT, and PAL. Triglycerides and cholesterol levels not differ between groups $(P>0.05)$.

\section{Discussion}

In this study, dogs naturally infected by $E$. canis showed two phases of the disease. Dogs acutely infected showed decreased hematocrit when compared to dogs in the subclinical form of canine ehrlichiosis or to those uninfected animals. These results corroborate with Castro [9] and Villaescusa [23], which found reduced levels of erythrocytes and hemoglobin in infected dogs, indicating a possible anemia due to hemolysis. We also evidenced clinical signs on infected animals such as apathy, appetite loss, and fever as previously described by Da Silva et al. [5]. Although animals with acute ehrlichiosis showed higher ALT and AST, we were unable to correlate these finding to liver injury, since these parameters were within normal range for the species and they may not have clinical relevance.

Based on the $\mathrm{NO}_{x}$ and cytokines results, it is possible to assure that there was an immunological response against $E$. canis in dogs with the subclinical and acute phases of the disease. However, in the acute phase, the inflammatory response was stronger. This conclusion was based on the following findings: higher $\mathrm{NO}_{x}$ and pro-inflammatory cytokines levels compared to lower anti-inflammatory cytokine (IL-10) on the same animals. Similar findings have been described in experimental infection by E. canis $[5,10]$ in dogs.

A positive correlation between BChE activity and proinflammatory cytokines or markers of hepatic injury was observed in dogs with the acute form of the disease caused by E. canis, i.e. all these variables were increased in canine sera. Based on our data, it is possible to assure that BChE is actively involved in the inflammatory response of canine ehrlichiosis, since BChE is a serine hydrolase that catalyzes the hydrolysis of esters of choline, but can also take AChE role in acetylcholine degradation when acetylcholinesterase is inhibited or absent [24]. Then, when there is an increase in the AChE and/or BChE activities, a rapid degradation of ACh occurs, which is considered an anti-inflammatory molecule that binds to nicotinic receptors in lymphocytes surfaces. As a result, there is an inhibition of cytokines, serotonin, histamine, nitric oxide, lysosomal enzymes, prostaglandins, and leukotrienes, known as mediators of the inflammatory process $[12,15,25,26]$. Therefore, we suggest that the inflammation triggered by the $E$. canis infection leaded to BChE activity increase and, as an outcome, there is a decrease of $\mathrm{ACh}$, which possess anti-inflammatory properties. Our results also show a probable hepatic injury proved by ALT and AST increase in the acute phase of the disease, which could interfere with the hepatic synthesis of BChE [16].

The negative correlation found between BChE and markers of immune response or liver injury on animals with the subclinical phase of ehrlichiosis could be explained by two different ways: BChE levels are strongly influenced by inflammation, and it can be decreased dramatically in the acute inflammatory phase [27]. Moreover, positive acute-phase proteins, such as C-reactive protein (CRP), may increase during inflammatory diseases; negative acute-phase proteins (albumin, prealbumin, and transferrin) inversely respond $[28,29]$. These proteins reflect cytokine induced stress and catabolism, which in turn, affect patient's clinical condition even for those with subclinical disease. Due to its short half-life, some authors speculate the usefulness of seric BChE as a nutritional and prognostic marker since it rapidly changes under general clinical conditions and nutritional status [30]. The second way (not excluding the first) to explain negative correlation between $\mathrm{BChE}$ versus markers of immune response or liver injury is the fact that $\mathrm{BChE}$ is synthesized in the liver, thus, hepatocellular impairment could decrease the amount of BChE. In fact, its plasma levels decrease in acute and chronic liver damage, cirrhosis, and liver metastases, being a biochemical marker of organ 
BChE vs TNF Treatment groups

Acute • Control $\square$

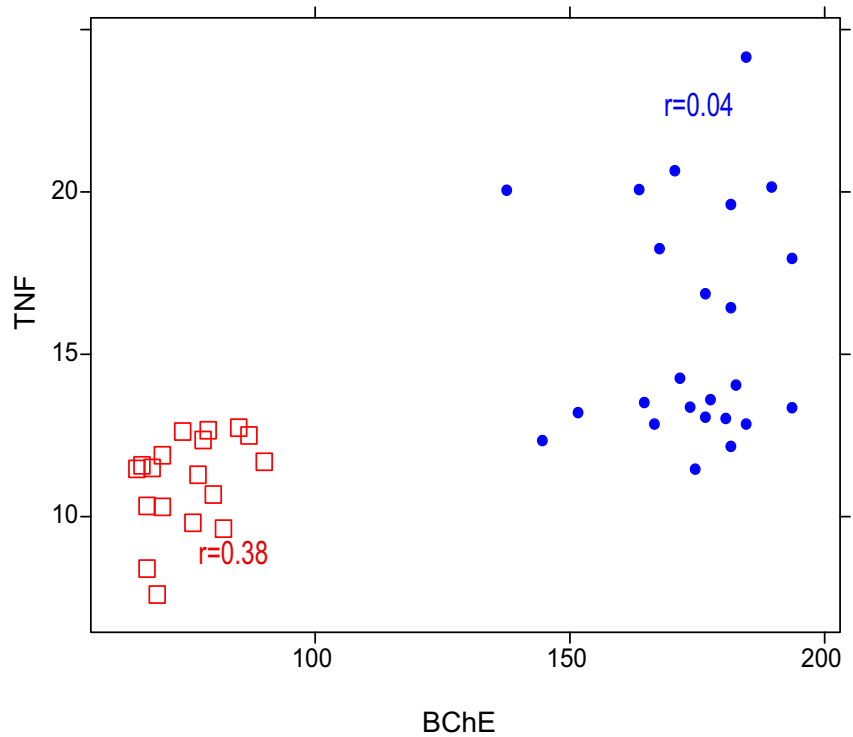

BChE vs IFN Treatment groups

Acute • Control

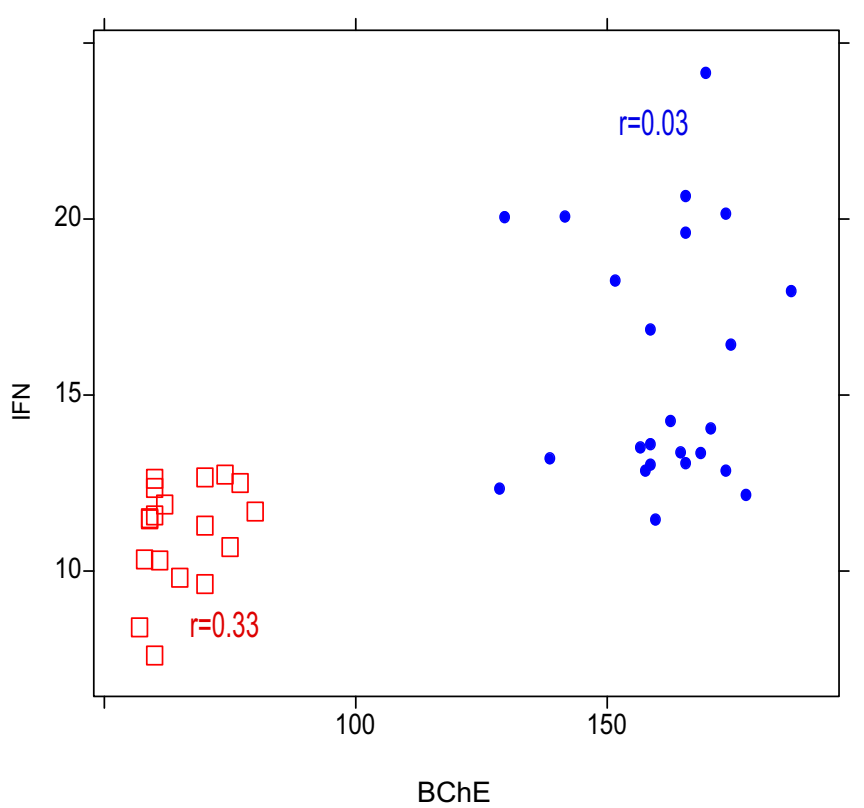

BChE vs TNF Treatment groups

Subclinical • Control $\square$

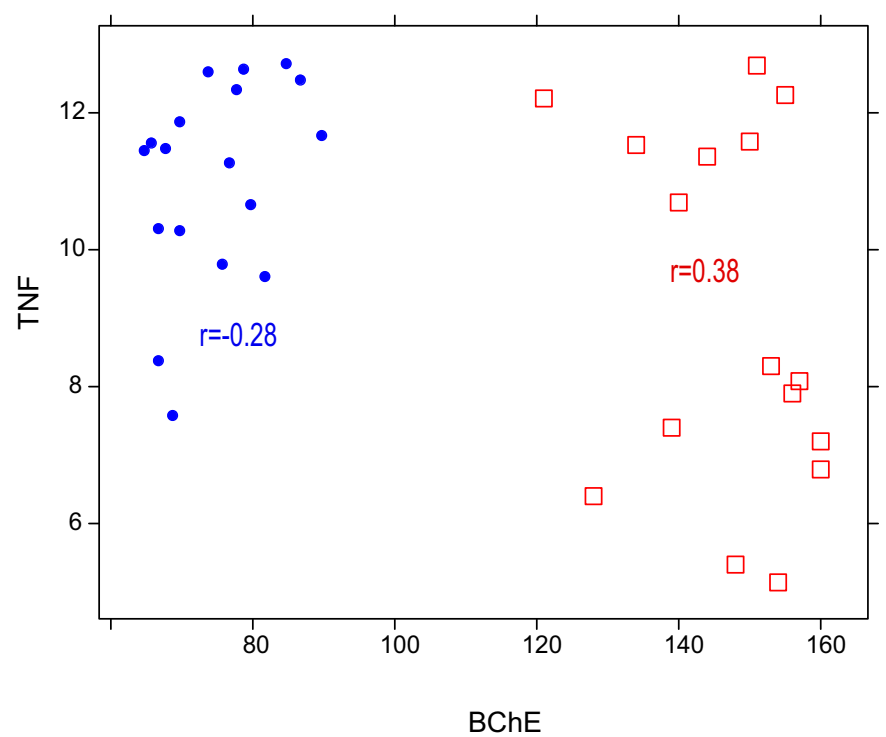

BChE vs IFN Treatment groups

Subclinical • Control $\square$

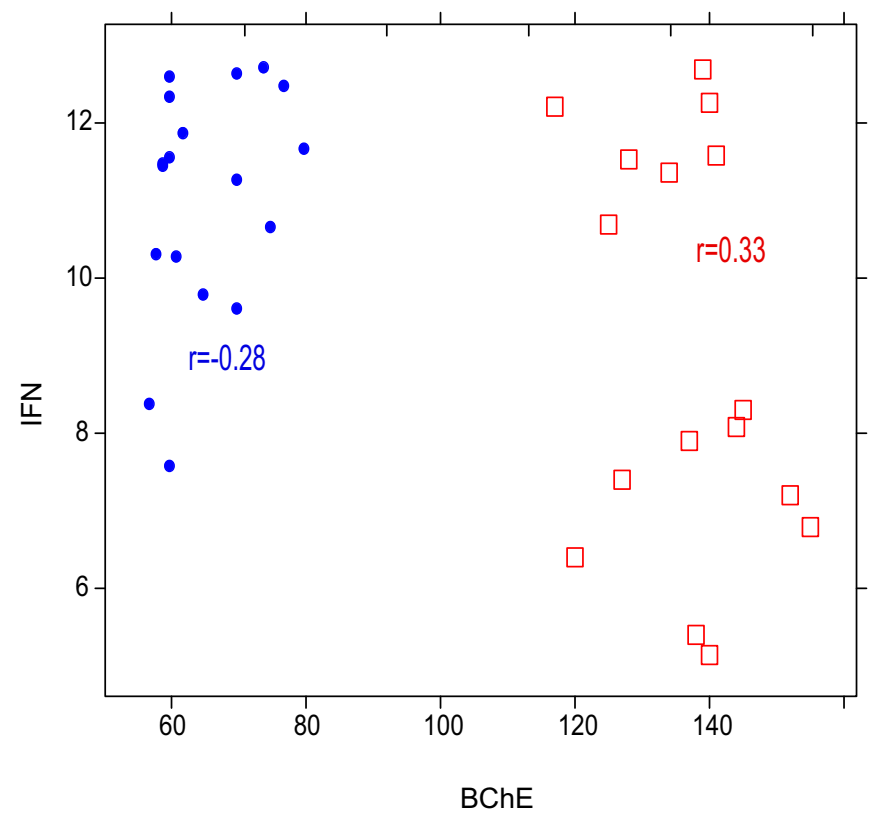

Fig. 2. Correlation between BChE versus TNF- $\alpha$ and BChE versus INF- $\gamma$ considering: control group and acute phase group; and control group and subclinical group.

Table 2

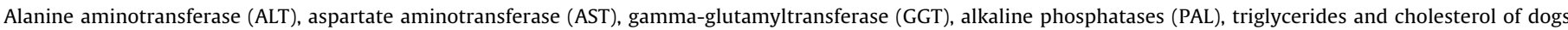
natural infected by Ehrlichia canis (acute and chronic phases) compared with healthy dogs (control).

\begin{tabular}{|c|c|c|c|}
\hline Variables & Healthy dogs (control) & Infected dogs (acute phase) & Infected dogs (subclinical) \\
\hline $\operatorname{ALT}\left(\mathrm{UL}^{-1}\right)$ & $29.5(11.0-48.0)^{\mathrm{c}}$ & $37.5(26.0-74.0)^{\mathrm{a}}$ & $24(15.0-59.0)^{b}$ \\
\hline AST $\left(U^{-1}\right)$ & $27.5(9.0-47.0)^{c}$ & $40.5(19.0-80.0)^{a}$ & $33(13.0-67.0)^{b}$ \\
\hline GGT $\left(\mathrm{UL}^{-1}\right)$ & $3.4(1.2-4.2)^{c}$ & $4.35(2.8-5.6)^{\mathrm{b}}$ & $6.4(4.6-8.2)^{\mathrm{a}}$ \\
\hline $\operatorname{PAL}\left(\mathrm{UL}^{-1}\right)$ & $23.4(18.1-29.7)^{c}$ & $39.3(21.3-56.4)^{\mathrm{b}}$ & $73.4(48.9-120.3)^{\mathrm{a}}$ \\
\hline Triglycerides $\left(\mathrm{mg} \mathrm{dL}^{-1}\right)$ & $45.3(23.7-66.7)^{\mathrm{a}}$ & $33.4(21.2-57.5)^{\mathrm{a}}$ & $40.8(27.5-69.4)^{\mathrm{a}}$ \\
\hline Cholesterol ( $\left.\mathrm{mg} \mathrm{dL}^{-1}\right)$ & $125.4(89.4-187.0)^{\mathrm{a}}$ & $109.1(81.2-130.1)^{a}$ & $121.2(77.9-174.2)^{\mathrm{a}}$ \\
\hline
\end{tabular}

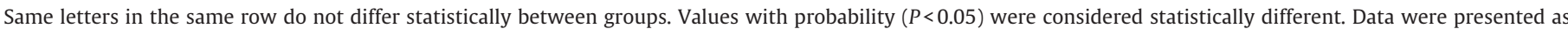
median values and the range (minimum-maximum). 


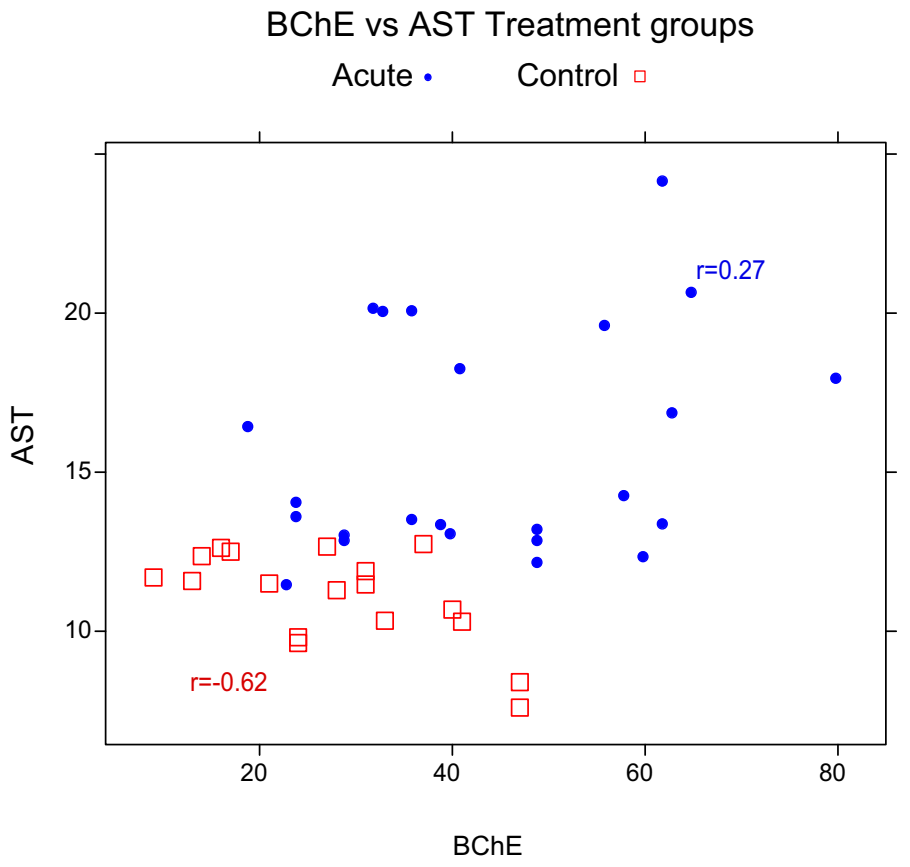

BChE vs ALT Treatment groups

Acute - Control $\square$

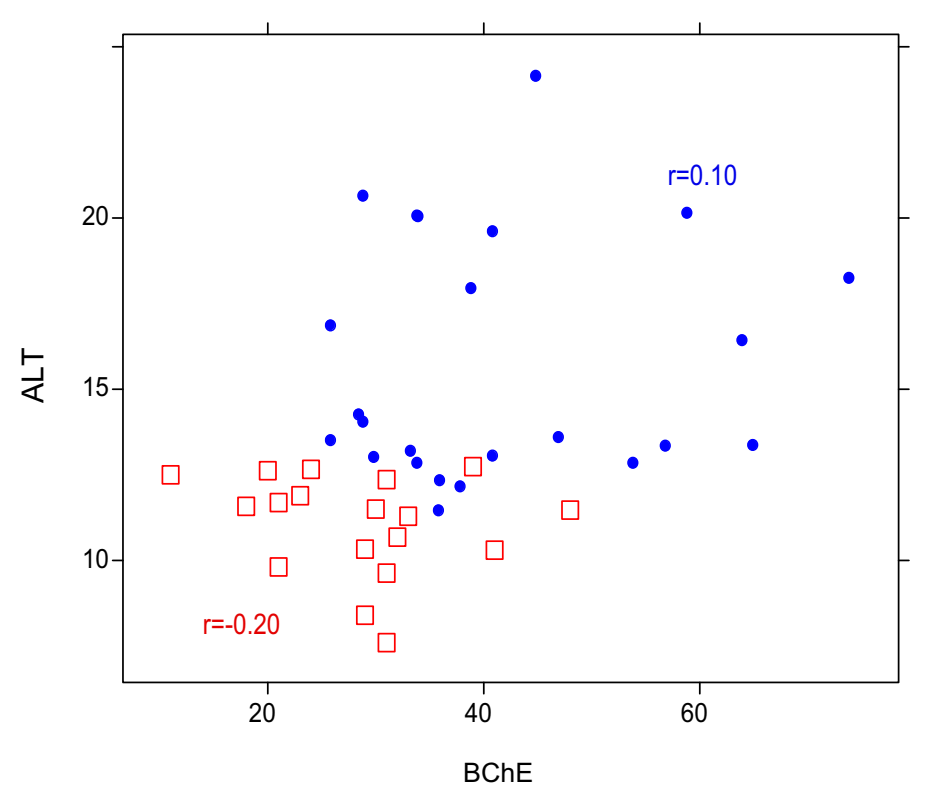

BChE vs AST Treatment groups

Subclinical • Control $\square$

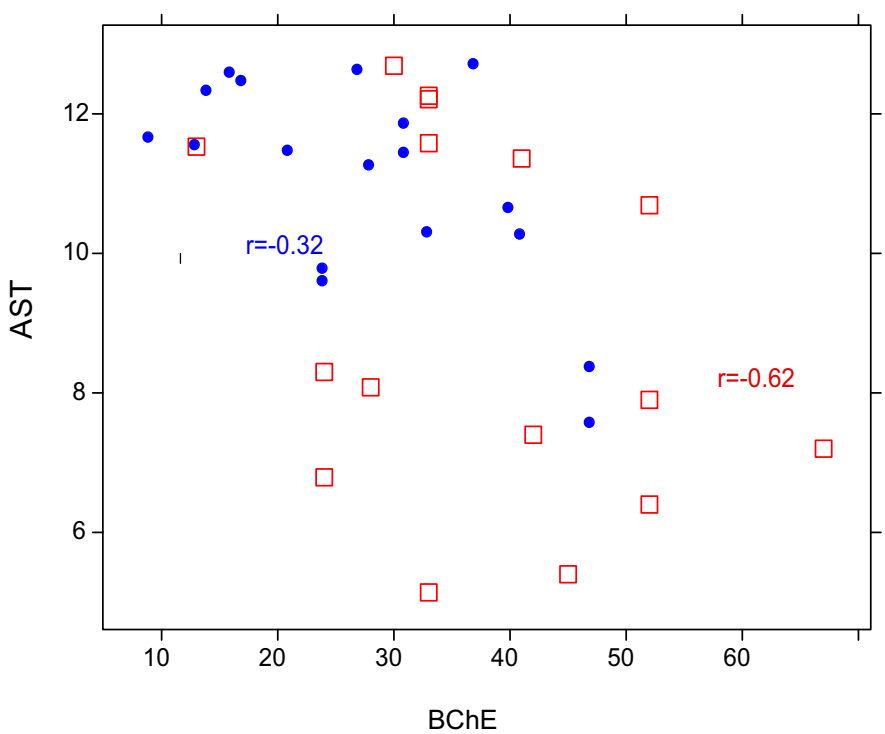

BChE vs ALT Treatment groups

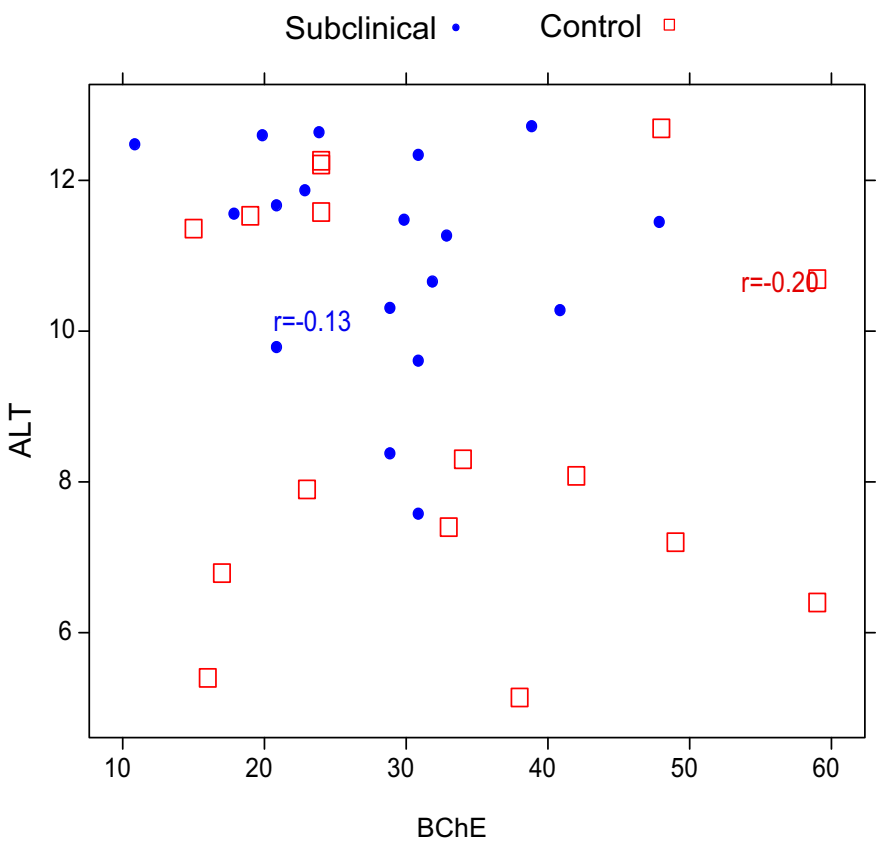

Fig. 3. Correlation between BChE versus AST and BChE versus ALT considering: control group and acute phase group; and control group and subclinical group.

injury [13]. Considering that, severe hepatitis in E. canis infection may lead [31] to liver hyperplasia and increased liver-specific enzymatic activities such as alanine transaminase and alkaline phosphatase that have been reported in dogs with acute phase of the disease [32,33], similarly to what was observed in this current study.

Based on these results, we conclude that the role of BChE in canine ehrlichiosis is different on the acute and subclinical phases, where acute infection leads to increased seric BChE activity, as well as to inflammatory mediators measured in this study. Therefore, this enzyme can be used as a marker for inflammatory responses during the acute phase of $E$. canis infection on naturally infected dogs. In the subclinical phase, the dogs showed a reduction in $\mathrm{BChE}$ activity, which has probably occurred by hepatic lesions, which may be interfering with hepatic enzymatic synthesis.

\section{Commission of ethics and animal welfare}

The present study was approved by the Ethics Committee for Use of Animals (CEUA) of Universidade Estadual Paulista (UNESP), Jaboticabal Campus, under protocol number 010290/14. 


\section{Conflict of interest statement}

\section{The authors have declared no conflict of interest.}

\section{References}

[1] B. Davoust, J.L. Marié, S. Mercier, M. Boni, A. Vandeweghe, D. Parzy, F. Beugnet, Assay of fipronil efficacy to prevent canine monocytic ehrlichiosis in endemic areas, Vet. Parasitol. 112 (2003) 91-100.

[2] B. Davoust, D. Parzy, D. Jean-Paul, R. Tine, M. Diarra, M. Jean-Lou, O. Mediannikov, Usefulness of a rapid immuno-migration test for the detection of canine monocytic ehrlichiosis in Africa, Comp. Immunol. Microbiol. Infect. Dis. 37 (2014) 31-37.

[3] M.E. Mylonakis, P.G. Xenoulis, K. Theodorou, V.I. Siarkou, J.M. Steiner, S, Harrus, L. Leontides, T. Rallis, J.S. Suchodolski, C.K. Koutinas, A.F. Koutinas, Serum canine pancreatic lipase immunoreactivity in experimentally induced and naturally occurring canine monocytic ehrlichiosis (Ehrlichia canis), Vet. Microbiol. 169 (2014) 198-202.

[4] A. Shipov, E. Klement, L. Reuveni-Tager, T. Waner, S. Harrus, Prognostic indicators for canine monocytic ehrlichiosis, Vet. Parasitol. 153 (2008) $131-138$

[5] A.S. Da Silva, T.D. Munhoz, J.L.M. Faria, G.V. Hérnandez, R.Z. Machado, N.C. Luz, C.E.J. Moritz, E.A. Casali, N.B. Bottari, L.M. Stefani, M.T. Costa, Influence of experimental canine ehrlichiosis on the E-ADA activity and purine levels in serum and possible functional correlations with pathogenesis, Vet. Microbiol. 166 (2013) 602-606.

[6] S.M. Trapp, A.S. Dagnone, O. Vidotto, R.L. Freire, A.M. Amude, A.H.S. Morais, Seroepidemiology of canine babesiosis and ehrlichiosis in a hospital population, Vet. Parasitol. 140 (2006) 223-230.

[7] P.R. Hess, R.V. English, B.C. Hegarty, G.D. Brown, E.B. Breitschwerdt Experimental Ehrlichia canis infection in the dog does not cause immunosuppression, Vet. Immunol. Immunopathol. 109 (2006) 117-125.

[8] L.A. Cohn, Ehrlichiosis related infections, Vet. Clin. N. Am. Small Anim. Pract. 33 (2003) 863-884.

[9] M.B. Castro, R.Z. Machado, L.P.C.T. Aquino, A.C. Alessi, M.T. Costa, Experimental acute canine monocytic ehrlichiosis: clinicopathological and immunopathological findings, Vet. Parasitol. 119 (2004) 73-86.

[10] J.L.M. Faria, T.D. Munhoz, C.F. João, G. Vargas-Hernández, M.R. Andre, W.A.B. Pereira, R.Z. Machado, M. Tinucci-Costa, Ehrlichia canis (Jaboticabal strain) induces the expression of TNF- $\alpha$ in leukocytes and splenocytes of experimentally infected dogs, Rev. Bras. Parasitol. Vet. 20 (2011) 71-74.

[11] A. Beineke, S. Markus, J. Borlak, T. Thum, W. Baumgärtner, Increase of pro-inflammatory cytokine expression in non demyelinating early cerebra lesions in nervous canine distemper, Viral Immunol. 21 (2008) 401-410.

[12] U.N. DAS, Acetylcholinesterase and butyrylcholinesterase as possible markers of low-grade systemic inflammation, Med. Sci. Monit. 13 (2007) 214-221.

[13] L. Santarpia, I. Grandone, F. Contaldo, F. Pasanisi, Butyrylcholinesterase as a prognostic marker: a review of the literature, J. Cachexia Sarcopenia Muscle 4 (2013) 31-39.

[14] G.A. Reid, N. Chilukuri, S. Darvesh, Butyrylcholinesterase and the cholinergic system, Neuroscience 234 (2013) 53-68.

[15] K. Kawashima, T. Fujii, The lymphocytic cholinergic system and its contribution to the regulation of immune activity, Life Sci. 74 (2003) 675-696.
[16] M.D. Stojanov, D.M. Jovičić, S.P. Djurić, M.M. Konjević, Z.M. Todorović, M.S Prostran, Butyrylcholinesterase activity and mortality risk in hemodialysis patients: comparison to hsCRP and albumin, Clin. Biochem. 42 (2009) 22-26.

[17] A.A. Rao, G.R. Sridhar, U.N. Das, Elevated butyrylcholinesterase and acetylcholinesterase may predict the development of type 2 diabetes mellitus and Alzheimer's disease, Med. Hypotheses 69 (2007) 1272-1276.

[18] H. Inokuma, K. Fujii, M. Okuda, T. Onishi, J.P. Beaufils, D. Raoult, P. Brouqui, Determination of the nucleotide sequences of heat shock operon groESL and the citrate synthase gene (gltA) of anaplasma (Ehrlichia) platys for phylogenetic and diagnostic studies, Clin. Diagn. Lab. Immunol. 9 (2002) 1132-1136.

[19] C. Bulla, R.K. Takahir, J.P. Araujo Jr., L.A. Trinca, R.S. Lopes, C.E. Wiedmeyer, The relationship between the degree of thrombocytopenia and infection with Ehrlichia canis in an endemic area, Vet. Res. 34 (2003) 1-6.

[20] A.J. Birkenheuer, M.G. Levy, E.B. Breitschwerdt, Development and evaluation of a seminested PCR for detection and differentiation of Babesia gibsoni (Asian Genotype) and B. canis DNA in canine blood samples, J. Clin. Microbiol. 41 (2003) 4172-4177.

[21] G.L. Ellman, K.D. Courtney, V. Andres, R.M. Feather-Stone, A new and rapid colorimetric determination of acetylcholinesterase activity, Biochem. Pharmacol. 7 (1961) 88-95.

[22] E. Tatsch, G.V. Bochi, R.S. Pereira, H. Kober, J.R. Oliveira, R.N. Moresco, A simple and inexpensive automated technique for measurement of serum nitrite/nitrate, Clin. Biochem. 44 (2011) 348-350.

[23] A. Villaescusa, M.A. Tesouro, M. García-Sancho, T. Ayllón, F. Rodríguez-Franco, A. Sainz, Evaluation of lymphocyte populations in dogs naturally infected by Ehrlichia canis with and without clinical signs, Ticks Tick-borne Dis. 3 (2012) 278-281.

[24] B. Li, J.A. Stribley, A. Ticu, W. Xie, L.M. Schopfer, P. Hammond, S. Brimijoin, S.H. Hinrichs, O. Lockridge, Abundant tissue butyrylcholinesterase and its possible function in the acetylcholinesterase knockout mouse, J. Neurochem. 75 (2000) 1320-1331.

[25] C.J. Czura, K.J. Tracey, Autonomic neural regulation of immunity, J. Intern. Med. 257 (2005) 156-166.

[26] E. Nizri, Y. Hamra-Amitay, C. Sicsic, I. Lavon, T. Brenner, Anti-inflammatory properties of cholinergic up-regulation: a new role for acetylcholinesterase inhibitors, Neuropharmacology 50 (2006) 540-547.

[27] R.E. Hubbard, M.S. O'Mahony, B.L. Calver, K.W. Woodhouse, Plasma esterases and inflammation in ageing and frailty, Eur. J. Clin. Pharmacol. 64 (2008) 895-900.

[28] M.P. Fuhrman, P. Charney, C.M. Mueller, Hepatic proteins and nutrition assessment, J. Am. Diet. Assoc. 104 (2004) 1258-1264.

[29] P.B. Soeters, A.M. Schols, Advances in understanding and assessing malnutrition, Curr. Opin. Clin. Nutr. Metab. Care 12 (2009) 487-494.

[30] L. Davis, J.J. Britten, M. Morgan, Cholinesterase. Its significance in anaesthetic practice, Anaesthesia 52 (1997) 244-260

[31] M.E. Mylonakis, M. Kritsepi-Konstantinou, J.S. Dumler, P.P. Diniz, M.J. Day, V.I. Siarkou, E.B. Breitschwerdt, V. Psychas, T. Petanides, A.F. Koutinas, Severe hepatitis associated with acute Ehrlichia canis infectionin a dog, J. Vet. Intern. Med. 24 (2010) 633-638.

[32] R.C. Dillman, E.H. Coles, A canine serum fraction analogous to human C-reactive protein, Am. J. Vet. Res. 27 (1966) 1769-1775.

[33] M.J. Reardon, K.R. Pierce, Acute experimental canine ehrlichiosis, Vet. Pathol. 18 (1981) 48-61. 